\title{
O MACHADO TERRA-A-TERRA DE JOHN GLEDSON
}

POR UM NOVO MACHADO DE ASSIS,

de John Gledson. São Paulo: Companhia das Letras, 2006.

HÉlio de SEIXAS GUimarÃes

Um escritor dotado de "um pensamento histórico", com idéias próprias sobre a história brasileira, fascinado com a questão problemática da unidade de uma nação fraturada, e que a certa altura passa a enxergar o Brasil como um país incapaz de uma verdadeira organização, adotando uma postura política pessimista. Para ele, os homens não dividem o poder naturalmente nem com boa vontade: querem sempre mais para si. Pessimismo não é o mesmo que fatalismo. Mesmo nos momentos de franco desespero, nunca deixou de se interessar pela sorte do seu país.

Patriota e nacionalista discreto, menos um ideólogo que um homem curioso pelo movimento da história, no fundo indiferente às denominações partidárias e aos regimes, dos quais lhe interessavam principalmente as raízes históricas e sociais. Um escritor que odiava a escravidão e, a seu modo, fez tudo para combatê-la, mas que também tinha a convicção de que os efeitos do escravismo eram profundos demais para serem eliminados por meio de uma lei, de modo que a euforia pública diante da abolição poderia servir para acobertar a liberdade ilusória dos escravos, apenas transferidos de um regime opressivo para outro. Da mesma maneira, a certa altura percebeu que a mudança para o regime republicano não implicaria alteração significativa na estrutura de poder.

Daí ter-se mantido monarquista, fiel à figura de d. Pedro II, favorável ao centralismo do Império, simpático ao sistema parlamentar, descrente da República, porque previa que esta se assentaria sobre um federalismo oligárquico, deslocando o poder para os oligarcas regionais, sobretudo os paulistas, o que poderia abrir espaço para uma ditadura - o que de fato ocorreu com a subida de Floriano Peixoto ao poder. Por isso o silêncio do cronista na transição do Império para a República, quando por alguns meses suspendeu sua atividade 
nos jornais, temendo que o Brasil perdesse o rumo, e ele, a lucidez diante da situação.

Um escritor profundamente marcado pela experiência como cronista, atividade em que a interlocução é fundamental; mas que ao longo da vida se tornou cada vez mais consciente da distância que havia entre ele e seus leitores. Daí a falta e a precariedade da comunicação se tornarem assuntos que tanto o fascinaram, manifestando-se também na tensão crescente e estrutural da sua relação com o leitor ficcional. Conhecedor da mentalidade do seu público, bem como das possibilidades e limitações dos veículos com os quais colaborou, soube como poucos modular sua escrita e jogar com as expectativas e preconceitos dos seus leitores e leitoras.

Um escritor profundamente irônico, que intencionalmente inscreveu, sob a superfície dos seus textos, níveis de sentido que contrariam sistematicamente tudo o que está dito na superfície, cabendo ao leitor juntar e montar as peças, para extrair um sentido que muitas vezes se estabelece na contramão das percepções dos próprios narradores.

Um escritor que compreendeu as mulheres e entendeu suas limitações não como inerentes ao gênero feminino, mas às restrições a elas impostas pela sociedade conservadora, o que permite chamá-lo de feminista. Ao mesmo tempo, um homem que encarou o sexo não no seu aspecto fisiológico, segundo a voga naturalista, mas na importância específica que pode assumir nas relações entre as pessoas, e também como instrumento de opressão e poder.

Um escritor que "cada vez mais percebeu o mundo como o domínio da falsidade, um tecido infinitamente complexo de inverdades e meias verdades", que terminou seus dias junto com o velho Rio de Janeiro, cuja demolição testemunhou durante as reformas urbanas do início do século XX.

Esseé,em linhas muito gerais, o Machado de Assis que surge da leitura de uma coletânea de catorze ensaios de John Gledson escritos e publicados ao longo dos últimos vinte anos. Reunidos agora em livro edispostos como capítulos independentes, os ensaios foram cuidadosamente "alinhavados" para a nova edição. Criam, assim, um conjunto coeso, dando uma idéia muito nítida da coerência do pensamento do crítico e do modo como ele tem lido, analisado e interpretado a obra do autor desde que pela primeira vez se dedicou a escrever sobre ela, em 1983, em um artigo sobre Casa velha, novela até então praticamente ignorada pela crítica.

Esse novo Machado, que se configura a partir de um longo e intenso convívio de Gledson com o escritor, vem contrapor-se ao que seria o "velho" Machado: absenteísta, apolítico, pudico nas 
[1] Cf. John Gledson, Machado de Assis: impostura e realismo - Uma reinterpretação de Dom Casmurro (Companhia das Letras, 1991), p. 13 O livro saiu em inglês com o título The deceptive realism of Machado de Assis $A$ dissenting interpretation of Dom Casmurro (Francis Cairns, 1984).

[2] John Gledson, Machado de Assis - Ficção e história (Paz e Terra, 1986, com 2- ed. revista e ampliada de 2003). questões de sexo, escapista, um homem que, no seu processo pessoal de aburguesamento, deu as costas às questões sociais e, uma vez consagrado, habitou a torre de marfim de onde presidiu tranqüilo uma época literária sem grandes turbulências. O Machado de Assis descoberto por John Gledson é um homem que construiu sua obra com os pés na terra, no corpo-a-corpo com as questões grandes e pequenas de sua época.

Embora todos os ensaios já tenham sido publicados anteriormente, vários foram significativamente modificados, de modo a incorporar estudos recentes sobre o escritor, bem como discussões e polêmicas surgidas a partir de suas publicações originais. Em alguns casos, para esclarecer seus argumentos, Gledson acrescentou parágrafos e até páginas inteiras às versões anteriores, como ocorre nos três capítulos em torno da crônica machadiana, intitulados "Bons dias!", "O patriotismo de Machado de Assis: uma crônica de 1892 " e "A semana' 1892-3: uma introdução aos primeiros anos da série".

Nesses ensaios, as modificações retomam - mas também colocam em discussão - as duas principais proposições de Gledson sobre a vida e a obra do escritor, que aparecem em suas obras publicadas nos anos 1980 . Em Machado de Assis: impostura e realismo, que tem como subtítulo "Uma reinterpretação de Dom Casmurro", Gledson defende que o romance de 1899-1900 se insere no âmbito do realismo, entendido como "a intenção do romancista de revelar, através da ficção, a verdadeira natureza da sociedade que está retratando". ${ }^{1} \mathrm{Na}$ obra seguinte, Ficção e história, o crítico ampliava o argumento, propondo que o conjunto da ficção de Machado contém uma interpretação sistemática, organizada e original do processo histórico brasileiro. ${ }^{2}$

$\mathrm{Na}$ linha do que Raymundo Faoro e Roberto Schwarz tinham acabado de fazer na década de 1970, e francamente inspirado por $A$ pirâmide e o trapézio e Ao vencedoras batatas, Gledson mostrava que o projeto ficcional de Machado, por décadas e décadas encarado como alienado e indiferente aos processos sociais e históricos brasileiros, fora meticulosamente entretecido com fios da história local. Isso era demonstrado com a clareza e a simplicidade dos diagramas, construídos a partir de uma intimidade impressionante com a história do Brasil, inclusive nos seus detalhes mais insuspeitos e às vezes quase incríveis, muitos deles recuperados das velhas páginas de jornal. Em Ficção e história, as interpretações renovadoras de Casa velha, Quincas Borba, Esaúe Jacó e Memorial de Aires sustentam-se, em grande medida, no conhecimento abrangente da história brasileira e da produção cronística e jornalística do século XIX.

Neste novo livro, a crônica também tem lugar central. (A centralidadeé até mesmo física, já que nas duas obras os capítulos dedicados à crônica ocupam o meio do livro). Tanto lá como aqui, o ensaio sobre 
a série "Bons dias!" aparece como um ponto de articulação, em torno do qual se desenvolvem as interpretações das obras propriamente ficcionais de Machado. Tanto nos dois livros dos anos 1980 como neste, as discussões principais giram em torno do estatuto dos narradores das crônicas - e da relação do escritor empírico com eles - bem como das peculiaridades do realismo machadiano. Desta vez, Gledson retorna a essas questões fundamentais do seu projeto crítico (e da crítica machadiana desde os seus primórdios) para esclarecer o seu modo deler a obra de Machado de Assis, baseado no que define como "intencionismo mínimo".

Com firmeza, mas também fazendo graça, Gledson protesta contra o que seria a vulgarização do seu "método" de leitura, que faz com que qualquer barbado se torne d. Pedro II e qualquer número ou data dê ensejo aos cálculos mais complexos e arbitrários que nenhum mortal, de hoje ou de antanho, seria capaz de acompanhar.

Sua notável capacidade de estabelecer esse tipo de relação tornouse uma espécie de marca registrada, mas é tão pessoal que talvez seja mesmo intransferível. Sua leitura do conto "Capítulo dos chapéus" é magistral, mas provavelmente soaria como superinterpretação se feita por qualquer outro crítico. Em "O Mot de l'énigme, de Madame Craven, onze vezes", Gledson parte de um detalhe aparentemente banal - o fato de a protagonista do conto ter lido onze vezes um mesmo romance - para empreender um verdadeiro tour de force, buscando as possíveis intenções de Machado ao escrever que a personagem leu tantas vezes a obra de uma escritora obscura, a tal Madame Craven. Gledson inicia uma verdadeira investigação detetivesca, que passa por sebos em vários países e inclui a leitura de calhamaços de literatura insossa, para chegar a conclusões relativamente modestas. $\mathrm{O}$ crítico, mostrando a sempre saudável capacidade de distanciar-se de si mesmo e desconfiar um pouco das próprias obsessões, chega ao parágrafo final do ensaio pensando alto: "Talvez Madame Craven tenha me levado longe demais".

Tarde demais, porque o assunto, nascido de uma sensibilidade muito particular para o detalhe e de uma curiosidade genuína, ganha o maior interesse ao longo do ensaio, que se vai configurando como verdadeira aula sobre o processo de pesquisa, exposto com o desassombro que lembra o estilo de outra pesquisadora admirável, Marlyse Meyer, citada aliás por Gledson.

Para John Gledson, como se vê aqui e em todo o restante de sua obra (o que inclui também os livros dedicados à poesia de Drummond), a boa crítica pressupõe também pesquisa, e sua realização depende de questões materiais, concretas. Por isso, já na "Introdução" do livro, ele apresenta um roteiro das leituras que lhe importam na extensa fortuna crítica machadiana, ao mesmo tempo em que monta 
um programa para a reedição de obras fundamentais para a compreensão da vida e da obra, algumas há muito esgotadas, como é o caso da Bibliografia de Machado de Assis, de Galante de Sousa. O crítico inclui até mesmo um "guia rápido" para a produção de uma obra completa de Machado de Assis (que, por incrível que pareça, ainda está por ser feita), indicando também as melhores entre as edições disponíveis.

Assim, não surpreende (mas também surpreende, porque isso não está sedimentado nos hábitos locais) que já nas primeiras páginas Gledson apresente o seu entendimento do estado da arte da crítica machadiana, deixando claras as dívidas intelectuais, a maior delas com Roberto Schwarz, que lhe deu o "código de acesso" a Machado em Ao vencedor as batatas. Para Gledson, a crítica é tarefa eminentemente dinâmica e coletiva, que pressupõe o diálogo não só com luminares do passado, mas também com seus contemporâneos, sejam da mesma geração, mais velhos ou mais jovens. Também é notável o modo como o crítico trata com franqueza e respeito aqueles dos quais diverge, o que neste livro acontece principalmente em dois momentos: ao tratar dos "narradores das crônicas" e do realismo de Dom Casmurro, como veremos a seguir.

\section{O ESTATUTO dO “NARRADOR” DAS CRÔNICAS}

Em que medida o "narrador" das crônicas seria comparável a um narrador ficcional, como Brás Cubas e Dom Casmurro? E em que medida essa voz narrativa pode ser identificada com o escritor Machado deAssis? É em torno dessas questões e das suas possíveis respostas que giram os três capítulos inteiramente dedicados à crônica.

Respondendo principalmente ao historiador Sidney Chalhoub, John Gledson reafirma e defende a identificação entre a voz narrativa das crônicas e a voz do próprio Machado de Assis, considerando exagero, ou talvez incorreção, propor a existência, nas crônicas, de um "filtro narrativo" entre o escritor e a matéria narrada, à semelhança do que ocorre nos contos e nos romances. Para Gledson, nesses textos semijornalísticos o acesso ao pensamento do escritor seria substancialmente mais direto que nos contos e romances, em que o contato com a matéria narrada vem refratado - ou deformado - por narradores tendenciosos, não confiáveis, enganosos etc.

A divergência que se explicita aqui tem a ver com uma questão fundamental para o entendimento e a interpretação da obra de um escritor que parece se divertir em brincar de esconde-esconde com seus leitores. Mesmo os mais indiferentes e incuriosos de questões biográficas alguma vez, diante das obras desse escritor tão grandioso quanto esquivo, já devem ter se perguntado: o que nessa obra expressa a visão que Joaquim Maria tinha da vida, dos homens e do mundo?, qual o 
grau de antipatia e empatia desse homem com as histórias que escreve e com a galeria de patifes e pobres-diabos que criou?, até onde vai a ironia nesse texto?, e onde a ironia e o relativismo terminam, ou pelo menos arrefecem?

Para John Gledson, é na crônica que podemos flagrar melhor as opiniões e posições do escritor diante do mundo. É nelas que se pode perceber o interesse com que o escritor acompanhou as notícias e as questões do seu tempo, sistematicamente comentadas ali, ainda que de maneira tão oblíqua como o olhar de Capitu. A partir da pesquisa do noticiário que servia de matéria-prima para o cronista, e também do conhecimento detalhado da história e da crônica política brasileira, o crítico mostra com minúcia admirável e de modo convincente o corpoa-corpo de Machado com os costumes, as instituições e as questões sociais e políticas.

Essa constatação do interesse do escritor/cronista pelas coisas grandes e miúdas do seu tempo sustenta, tanto nas obras anteriores como neste novo livro de Gledson, a leitura da produção ficcional de Machado como sendo eminentemente realista. Um realismo peculiar, não pautado pelo ilusionismo nem pelo objetivismo, mas um realismo alegórico, dissimulado, enganoso, que contém, de maneira às vezes cifrada, uma interpretação crítica e abrangente do processo histórico e social brasileiro, intencionalmente inscrita por Machado em sua ficção. Esse "realismo historicamente consciente e detalhado" abrange desde o período colonial até o início da República, concentrando-se principalmente no Segundo Reinado (1840-1889), período que se estendeu por 49 dos 69 anos vividos por Machado e que dá o enquadramento temporal para boa parte de sua obra.

\section{CONTRA O RELATIVISMO TOTAL, MAS RELATIVIZANDO}

É em torno do realismo e das intenções do escritor que se desenvolve o outro núcleo polêmico do livro, concentrado no capítulo 9 , intitulado "Dom Casmurro: realismo e intencionismo revisitados". A discussão agora se dá com o crítico norte-americano Alfred Mac Adam e, sobretudo, com o crítico português Abel Barros Baptista. São do maior interesse as visões opostas que Gledson e Baptista têm da relação entre o narrador Bento e o "autor" do romance.3 Gledson defende ser possível em alguma medida identificar esse autor com Machado, identificação que Abel recusa, por defender que o que está em jogo em Dom Casmurro é justamente a crise da noção de autoria, ou sua ruína. Para o crítico português, que faz uma leitura "derridiana" do romance, o autor não pode mais ser pensado como lugar estável, garantidor do sentido último do texto e, portanto, não faria sentido falar em intenção do autor.
[3] Os argumentos de Abel Barros Baptista rebatidos por Gledson estão no artigo "O legado de Caldwell, ou o paradigma do péatrás", publicadoem Santa Barbara Portuguese Studies I (1994),pp.145-77. 
[4] Cf.Por um novo Machado de Assis, pp. 293-4.

[5] Cf. Por um novo Machado de Assis, p. 293.

[6] Cf. Por um novo Machado de Assis, p. 294 .
Contra o relativismo total, ou o que haveria de indecidível na leitura de um romance como Dom Casmurro, Gledson defende haver leituras mais ou menos corretas. Essa correção poderia ser medida a partir da identificação das intenções programadas por Machado de Assis. A intenção de Machado, para Gledson, estaria mais próxima da leitura mais politizada do romance, a que vê Bento Santiago como a conjunção execrável de refinamento e barbárie, um tipo de elite que usa modos sofisticados para explorar e destruir melhor quem ousar atravessar-lhe o caminho. Ou seja, a intenção de Machado com Dom Casmurro seria principalmente de denúncia social, embora isso pareça sair relativizado no percurso da discussão cerrada que estabelece com Abel Barros Baptista.

Isso não significa que o ataque à sociedade esteja ausente, ou seja secundário, mas Gledson parece considerar que a denúncia social talvez não seja o único propósito do romance, sobrepondo-se a tudo o mais. Haveria no romance algo mais que o tipo da elite perfeitamente apreendido por Roberto Schwarz em "A poesia envenenada de Dom Casmurro": Gledson reconhece que a identificação dos leitores com Bento se dá "não só por causa de um compromisso subconsciente com a elite brasileira". 4 Para isso, cita a si mesmo como evidência, já que, apesar de ser inglês e de classe média, a certa altura sentiu-se identificado - ou ludibriado - pelo narrador. Ou seja, o pacto do narrador Bento Santiago com o leitor firma-se sobre um componente brasileiro e de classe, mas não se esgota nele.

Nesse sentido, Gledson aponta para uma diferença importante entre o narrador em primeira pessoa de Brás Cubas e o de Dom Casmurro ao dizer que neste romance "o balanço possa ter se deslocado mais em direção à compreensão e ao perdão". 5 Compreensão, perdão, culpa, identificação, desprezo, tudo isso, e não só condenação, participa tanto da construção do narrador-personagem como da relação de Machado com Bento e também da relação que nós, leitores, estabelecemos com ele. Depois de considerar a tridimensionalidade do personagem-narrador Bento Santiago, com quem muitos leitores, em muitos níveis e em alguns momentos de leitura, se identificaram, Gledson propõe o seguinte: "Se forçarmos um pouco a barra: tal como Bento é um personagem e um autor tridimensionais, assim também é o leitor de Machado". 6

Embora concorde com Abel Barros Baptista que a ambigüidade radical do romance abre caminhos para as mais variadas interpretações - e que com isso Machado corria o risco de que "o conjunto das suas posições, das suas idéias, das suas intenções" ficasse coberto pelo manto dessa ambigüidade, como escreve Baptista no ensaio citado - Gledson argumenta, finalmente, que a configuração perfeitamente ambígua não quer dizer que o escritor não tivesse intenções claras com sua obra. 
Diante do equilíbrio perfeito, mas instável, que Machado construiu em Dom Casmurro, o que faz o pêndulo oscilar? Forçando a barra ou não, o interessante é que, quando se trata de Dom Casmurro, parece inescapável a entrada do leitor no circuito, já que as intenções do autor nunca estão explícitas, precisando ser atualizadas, em grande medida - ou quem sabe exclusivamente - por conta e risco do leitor, cujas intenções, essas sim, parecem se explicitar mediante qualquer gesto interpretativo. Num caso-limite como o de Dom Casmurro, será que a intenção atribuída ao autor não é indissociável da intenção do leitor?

O intencionismo aqui parece chegar ao seu limite - não no sentido de se tornar ineficaz como instrumento crítico, mas no sentido de que o romance de Machado parece sugerir a existência de algum tipo de dinâmica entre as intenções do autor empírico, que viveu no século XIX, e as intenções com as quais os leitores de diferentes tempos e lugares se aproximam do romance. Pensando-se que o sentido da obra esteja dado pela intenção do autor, a recepção de Dom Casmurro dominante por tantas décadas seria marcada pelo erro, e nada teria a nos dizer a respeito da própria configuração do romance? Se assim for, não estaríamos diante de um romance fracassado, já que as intenções demoraram tanto tempo para produzir, e ainda assim parcialmente, seu efeito? Uma vez reveladas as intenções do autor, o que restaria aos leitores e críticos do futuro?

Questões teóricas dessa natureza vão sendo suscitadas pela leitura do capítulo sobre o realismo e o intencionismo, certamente o de argumentação mais tensa e cerrada de todo o livro. Mesmo quando se opõe frontalmente às idéias de Baptista, a crítica de Gledson está balizada pela atenção tanto ao texto de Machado como ao de Baptista.

\section{INTENCIONISMO MÍNIMO}

Apesar de mais interessado nos fatos (tanto empíricos como ficcionais) que em teorias ou pressupostos rígidos, John Gledson reafirma que sua principal baliza teórica está no "intencionismo". Muito fora dos hábitos da crítica praticada no Brasil, essa orientação já causou muita (e ainda causa certa) estranheza, o que acaba contando a favor da sua crítica, que, apesar disso, tem lugar central nos estudos machadianos. Em Impostura e realismo, o próprio John Gledson parecia ironizar esse estranhamento ao definir-se como "intencionalista confesso", como se houvesse ou devesse haver alguma culpa embutida nisso. Agora sua posição aparece matizada pelo adjetivo "mínimo".

O intencionismo tem a ver com a formação do crítico, que estudou na Universidade de Princeton nos anos 1960 e 70 e encontrou na teoria de E. D. Hirsch uma espécie de antídoto aos excessos formalistas então dominantes na academia norte-americana. No tão famoso 
[7] Cf. Por um novo Machado de Assis, p. 96. quanto controverso Validity in interpretation (1967), Hirsch procurava estabelecer princípios de interpretação baseados nas intenções do autor, contrapondo-se ao New Criticism, ao desconstrutivismo de Jacques Derrida e ao pós-estruturalismo de Michel Foucault e Roland Barthes, que àquela altura dos anos 1960 proclamou a morte do autor em ensaio que se tornaria famoso.

Mas o que há de normativo e rígido na teoria de base formulada por Hirsch acaba se tornando mais maleável, também pelo embate da inteligência do crítico com a obra de Machado, cuja complexidade talvez convide mais à formulação de novas teorias que à aplicação das já existentes, como se nota na leitura do capítulo sobre Dom Casmurro comentado aqui.

Assim, o intencionismo de John Gledson não supõe que Machado de Assis tivesse clarividência sobre o que era a sociedade brasileira do século XIX e o processo histórico nos quais estava de alguma maneira imerso. Para Gledson, a intenção engloba também a sensibilidade e a intuição poderosas do escritor sobre o tempo e o lugar em que vivia, e sua genialidade, ou pelo menos parte dela, está na capacidade de trazer para o romance questões da formação social brasileira que nem haviam sido sistematizadas por estudos de história e sociologia, que a rigor só apareceriam a posteriori, com as teorias explicativas do Brasil formuladas ao longo do século XX. Intencionismo também não implica a possibilidade de identificação de uma intenção unívoca, coerente de início ao fim, mas de um conjunto de intenções que podem ser reconstituídas a partir do conhecimento de como o escritor refrata em diferentes personagens visões sobre um mesmo fato histórico. Nesse sentido, é interessante a observação de Gled son sobre as várias representações do episódio histórico da Maioridade de d. Pedro II na ficção de Machado:

Casa velha a vê como uma reação à ameaça de desintegração nacional, "Conto de escola", como uma questão de lutas e traições partidárias intestinas, Dom Casmurro, como um mito útil: essas são as perspectivas de 1839, maio de 1840 e 1857, respectivamente (e do Coronel Raimundo, Policarpo e Capitu).7

Diante dessa multiplicação de perspectivas sobre um mesmo episódio, cujo sentido explode diante da multiplicação de pontos de vista, como identificar a intenção do escritor Machado de Assis? Refratadas pelas opiniões e visões de seus personagens e narradores, que muitas vezes até discordam entre si, como descobrir a posição de Machado sobre esse ou qualquer outro episódio histórico? Em uma escrita marcada por segundas, terceiras e talvez enésimas intenções, como saber se a verdadeira intenção não é mais um dos sentidos enganosos que o texto de Machado nos induz a encontrar? 


\section{O LASTRO da CrôNICA}

Voltemos então à crônica, que de fato parece ocupar o centro do projeto crítico de John Gledson. Diante do terreno instável da ficção (instabilidade que Machado parece ter tido a intenção de levar às últimas conseqüências, multiplicando os filtros narrativos que nos separam, a nós leitores, daquilo que está sendo narrado), Gledson foi o primeiro a buscar no estudo sistemático da crônica a baliza mais segura e o terreno - relativamente - mais estável, do qual seria possível extrair as possíveis inclinações de Machado. "As crônicas são um meio privilegiado de entender a interação multifacetada entre o escritor e o mundo público em que se movia", escreve no ensaio sobre "Bons dias!".

As crônicas seriam o local onde, apesar da grande oscilação de tom e de opiniões, estaríamos mais próximos do pensamento e das convicções do intelectual, escritor e homem político Machado de Assis. Ainda que não constituam exatamente um repositório de idéias fixas, seriam a expressão das suas referências mais estáveis, algo como um estágio primeiro da estilização da matéria histórica, em direção ao processo de ficcionalização cada vez mais vertiginoso e labiríntico que se vê nos romances.

Isso não significa que, mesmo em textos produzidos ao correr da pena, marcados pela efemeridade do jornal, o escritor tenha dado de barato suas opiniões e posições políticas. Também ali estão cifradas as referências e alusões, por meio de recursos os mais engenhosos, como John Gledson tem mostrado. Exemplar disso, tanto em termos do procedimento de Machado como do tipo de análise empreendida por Gledson, é a crônica de 26 de novembro de 1893, publicada na Gazeta de Notícias. Nela, o cronista faz referência a um telegrama publicado em outro jornal, O Tempo, que trata da situação política na Grécia, onde deputados foram presos "por fazerem parte de uma quadrilha de salteadores". Gledson mostra como Machado, por meio do telegrama e da referência a realidades aparentemente remotas, fazia comentários precisos sobre os tempos bicudos da ditadura de Floriano Peixoto, dando conta da violência e dos descalabros em curso naqueles dias em que o Rio de Janeiro era palco de uma revolta naval e da repressão florianista.

Para compreender os deslocamentos operados por Machado, mestre em tratar da sua aldeia como quem trata da Grécia, e vice-versa, Gledson recompõe o contexto em que as crônicas foram publicadas. Isso às vezes exige conhecimento das notícias que freqüentavam não só os jornais em que Machado escrevia, mas as principais publicações do período, que o escritor lia regularmente e com as quais estabelecia intenso diálogo. Gledson foi o primeiro a propor e a realizar esse tra- 
balho de filigranista, que continua em andamento, agora também com a colaboração de Lúcia Granja, com quem publicará em breve a série de crônicas escritas em 1878 para OCruzeiro, o mesmo jornal em que saiu, em pedaços, a primeira versão de Iaiá Garcia.

A longa e ampla convivência com o conjunto das mais de seiscentas crônicas que Machado escreveu permite ao crítico auscultar a interação entre o escritor e o mundo, traçando relações e genealogias entre esses textos e o restante da obra, identificando questões recorrentes e indicando algumas das obsessões do escritor. Ao integrar esses textos "menores" à interpretação da obra machadiana, Gledson leva adiante uma convicção presente des de o início de sua produção crítica: a de que o projeto literário de Machado só será mais bem compreendido se formos além dos limites das obras ou dos gêneros individuais, incluindo escritos de todos os gêneros, maiores e menores, além do diálogo estreito e profícuo que Machado estabeleceu com as mais variadas tradições literárias.

Ao final da leitura do livro, que contém outros ensaios não comentados aqui, como o dedicado a OsMaias, de Eça de Queirós, e um outro sobre o aparecimento do tema da homossexualidade em Machado e Graciliano, a sensaçãoé de que, quanto mais conhecemos Machadoe parece inegável que hoje sabemos muito mais sobre o autor e sua obra do que jamais se soube, e os estudos de John Gledson representam um passo importante nessa compreensão contemporânea de um novo Machado -, mais deparamos com aporias, perguntas sem resposta, becos sem saída, estados de suspensão. São interrogações dentro de interrogações que a intrincada e superelaborada armação textual de Machado nos coloca à medida que vamos reconhecendo o tamanho do problema. Com John Gledson, o problema se torna maior e mais complexo, o que talvez seja o melhor indicativo da qualidade e da vitalidade de sua crítica, hoje incontornável para quem quiser estudar a sério a obra de Machado de Assis, em qualquer de suas manifestações.

HÉLIO DE SEIXAS GUIMARÃES é professor de literatura brasileira na USP, autor de Os leitores de Machado de Assis - o romance machadiano e o público de literatura no século 19 (Nankin/Edusp, 2004). 